\title{
Erratum to: Decline in Medicaid-Funded One-to-One Behavioral Support Use in School as Children Age
}

\author{
Christina D. Kang-Yi ${ }^{1} \cdot$ Jill Locke $^{2} \cdot$ Melanie Pellecchia $^{1} \cdot$ Steven C. Marcus $^{3} \cdot$ \\ Trevor Hadley ${ }^{1} \cdot$ David S. Mandell ${ }^{1,4}$
}

Published online: 22 February 2016

(C) Springer Science+Business Media New York 2016

\section{Erratum to: School Mental Health DOI 10.1007/s12310-015-9172-x}

The original version of this article unfortunately contained a mistake. The caption to Table 1 was incorrect. Table 1 was originally published in another journal, and the reference and permissions information was not included in the caption. The corrected caption is given now.
Table 1 Demographic characteristics by psychiatric disorder. Table reprinted with kind permission from Psychiatric Services, School-Based Behavioral Health Service Use and Expenditures for Children With Autism and Children With Other Disorders, Vol 67 (1), 2016, pages 101-106, Christina D. Kang-Yi, Jill Locke, Steven C. Marcus, Trevor R. Hadley, David S. Mandell, Table 1 (Copyright (C2015) American Psychiatric Association
The online version of the original article can be found under doi: 10.1007/s12310-015-9172-x.

Christina D. Kang-Yi

ckangyi@upenn.edu

Jill Locke

jjlocke@uw.edu

Melanie Pellecchia

pmelanie@upenn.edu

Steven C. Marcus

marcuss@upenn.edu

Trevor Hadley

thadley@upenn.edu

David S. Mandell

mandelld@upenn.edu
Center for Mental Health Policy and Services Research, Perelman School of Medicine, University of Pennsylvania, 3535 Market Street, 3rd Floor, Philadelphia, PA 19104, USA

2 Speech and Hearing Sciences, University of Washington Autism Center, University of Washington, Box 357920, Seattle, WA 98195, USA

3 School of Social Policy and Practice, University of Pennsylvania, Philadelphia, PA 19104, USA

4 Center for Autism Research, The Children's Hospital of Philadelphia, 3535 Market Street, 3rd Floor, Philadelphia, PA 19104, USA 